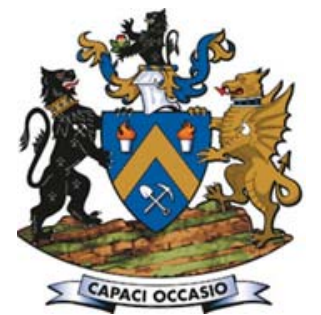

\title{
Evaluation of alternative solid media for coal beneficiation using an air dense- medium fluidized bed
}

\author{
by K.M. Chagwedera, S.o. Bada, and R.M.S. Falcon
}

\section{Synopsis}

A study was carried out to identify alternative dense media with potential for use in coal beneficiation in South Africa. Magnetite, pyrrhotite, silica sand, granulated blast furnace slag, and coal discards were tested. Magnetite and pyrrhotite provided the most uniform and stable bed densities, with bed density variation less than $0.7 \%$ and standard deviation less than $0.0025 \mathrm{~g} / \mathrm{cm}^{3}$. A $100 \%$ magnetite bed yielded a product with an ash content of about $20.30 \%$ and calorific value of about $25.24 \mathrm{MJ} / \mathrm{kg}$ from a feed coal of size fraction $-13+6 \mathrm{~mm}$ and ash content of $39.27 \%$. A cleaner coal product containg about $14.50 \%$ ash and with calorific value of 27.30 $\mathrm{MJ} / \mathrm{kg}$ was obtained from a bed of pyrrhotite and magnetite blend at a weight ratio of 40:60. The same blend reduced the total sulphur content from $2.49 \%$ in the feed coal to about $0.41 \%$ at a cut density of $1.63 \mathrm{~g} / \mathrm{cm}^{3}$ at a probable error (Ep) of 0.083 . The beneficiation of coal in a pure magnetite bed was not as effective as with the pyrrhotite-magnetite mixed bed.

\section{Keywords}

air separation, dense medium, fluidized bed, separation efficiency, bed stability. treating the large volumes of aqueous slurries generated during the wet process. In addition, coal beneficiated by dry methods retains a higher thermal heating value (Dwari and Rao, 2007). Air dense-medium fluidized bed (ADMFB) processes have been investigated for a number of decades and some of the results were patented as early as 1926 (Fraser and Yancey, 1926). The foundation for the industrial application of the ADMFB coal separation was based on studies conducted by different authors over the past decades. Zhao et al. (2016) present some of the most recent development in the industrial application of the ADMFB in the form of a large-scale (40-60 t/h) plant.

The solid medium material used in the ADMFB separator is one of the key factors for efficient coal separation. Magnetite has been widely used by other investigators. However, the demand for magnetite has increased because of its use in other industries such as steelmaking and catalysis, besides conventional wet coal beneficiation. In addition, the cost and future supply are of concern to the coal industry (Honaker and Bimpong, 2009). Some of the alternative solid media that have been investigated for use in the ADMFB include silica sand, silica-zircon mixtures, magnetic pearls, and paigeite. Azimi et al. (2013) used silica sand to achieve a recovery of $95.63 \%$, and clean coal ash content of $10.6 \%$, from a feed coal of $14.4 \%$ ash, at a separation efficiency of $15.29 \%$. Firdaus et al. (2012) used a bed of silica-zircon mixture and produced a clean coal product of about $9.71 \%$ ash at an Ep of 0.06, with $77.8 \%$ recovery. Similarly, paigeite ore has been used to reduce coal ash content from $22.37 \%$ to $9.88 \%$ with a

\footnotetext{
* Clean Coal and Sustainable Energy Research Group, Faculty of Engineering and the Built Environment, University of the Witwatersrand, South Africa.

(C) The Southern African Institute of Mining and Metallurgy, 2018. ISSN 2225-6253. Paper received Oct. 2017; revised paper received May 2018.
} 


\section{Evaluation of alternative solid media for coal beneficiation using an air dense-medium fluidized bed}

yield and Ep of $60.64 \%$ and 0.075 , respectively (Zhao et al., 2011). Magnetic pearls used by Luo et al. (2007) achieved an Ep value of 0.05 , with a coal product of $13.95 \%$ ash and yield of about $90.80 \%$.

This study focused on utilizing locally available alternative solid media materials in the ADMFB separator. The media tested include magnetite $\left(4880 \mathrm{~kg} / \mathrm{m}^{3}\right)$, pyrrhotite (2 $\left.983 \mathrm{~kg} / \mathrm{m}^{3}\right)$, granulated blast furnace slag (2 $\left.699 \mathrm{~kg} / \mathrm{m}^{3}\right)$, silica sand (2 $\left.410 \mathrm{~kg} / \mathrm{m}^{3}\right)$, and coal rejects (2 $\left.112 \mathrm{~kg} / \mathrm{m}^{3}\right)$. The use of pyrrhotite, alone or as a blend with magnetite, for a solid medium in an ADMFB application has not been reported before. Pyrrhotite, which is a reject dumped to tailings in nickel concentration and platinum group metals (PGMs) processing, has a density (approximately $3 \mathrm{~g} / \mathrm{cm}^{3}$ ) suitable for creating a fluidized bed and is known to occur in a magnetic form $\left(\mathrm{Fe}_{7} \mathrm{~S}_{8}\right)$, which aids in dense media recovery. These properties make pyrrhotite a potentially suitable dense medium for coal beneficiation in an ADMFB separator.

\section{Experimental}

\section{Materials}

The materials used in this study include the solid media, density tracers, and coal sourced from the Witbank coalfield in South Africa. The solid media were also obtained from different sources within South Africa and prepared in accordance with ISO 3082:2009 into the required size range $(-425+106 \mu \mathrm{m})$ for testing. Density tracers were used instead of coal to determine the best operating parameters and separation efficiency for each of the media utilized. The tracers were cube-shaped particles of $-13+6 \mathrm{~mm}$ size range, and within the density range $1.2-2.0 \mathrm{~kg} / \mathrm{m}^{3}$. The $100 \mathrm{~kg}$ coal bulk sample used for the test was prepared according to ISO 13909:2016 at a particle size range of $-13+6 \mathrm{~mm}$. Batch samples of $1 \mathrm{~kg}$ were subsequently used for the float-sink and the dry beneficiation experiments.

\section{Equipment}

The fluidized bed (Figure 1) used in this study was constructed from Perspex reinforced with a steel frame of a square cross-section of $40 \mathrm{~cm} \times 40 \mathrm{~cm}$ with a height of $60 \mathrm{~cm}$.

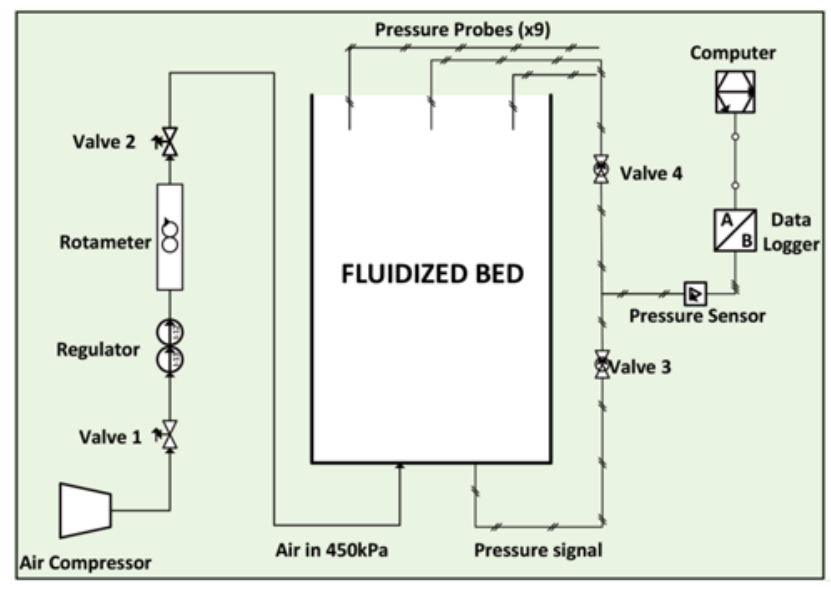

Figure 1-Experimental process flow diagram
Table I

Bed weights and corresponding static bed heights

\begin{tabular}{|l|c|c|c|}
\hline \multirow{2}{*}{ Bed material (kg) } & \multicolumn{3}{|c|}{ Static bed height } \\
\cline { 2 - 4 } & $\mathbf{2 0 ~ \mathbf { ~ m }}$ & $\mathbf{2 5} \mathbf{~ c m}$ & $\mathbf{3 0 ~} \mathbf{~ m}$ \\
\hline Magnetite & 94 & 117 & 141 \\
\hline Pyrrhotite & 57 & 72 & 86 \\
\hline GBFS* & 52 & 65 & 78 \\
\hline Silica sand & 46 & 58 & 69 \\
\hline Coal rejects & 41 & 51 & 61 \\
\hline
\end{tabular}

* GBFS: Granulated blast furnace slag

The distributor was made of a canvas material compacted between two sheets of wire mesh. The inlet air into the system was cleaned and dried by passing it through an air filter, and the pressure into the system was maintained at $450 \mathrm{kPa}(\mathrm{g})$. The pressure drop within the bed's crosssectional area was measured at nine different points using nine probes, each connected to a pressure transducer. The pressure readings were transformed through the transducers into electrical signal 'data' and recorded using an Agilent 34970A data logger.

\section{Test method}

The fluidized bed was loaded with one dense medium material at a time, with three static bed heights $(20,25$, and $30 \mathrm{~cm}$ ) used for each material. The approximate mass of each material in the fluidized bed is shown in Table I.

The operating velocity was determined and pressure drop measurements were taken at different points in the bed cross-section (plan view). A total of nine pressure point (A to I) readings were taken at bed heights of $0,5,10,15$, 20,25 , and $30 \mathrm{~cm}$ ) at a rate ot one reading per 500 milliseconds. Pressure drop profiles and density profiles were plotted, as seen in Figure 2. The process parameters such as superficial air velocity and static bed height were optimized through beneficiation tests using density tracers. A superficial air velocity of $12 \mathrm{~cm} / \mathrm{s}$, static bed height of $20 \mathrm{~cm}$, and separation time of 20 seconds were established. The solid medium with the best separation efficiency was selected as the dense medium material for coal beneficiation. The tests involved feeding $1 \mathrm{~kg}$ of coal into the fluidized bed and performing the separation at the established optimum conditions. A brush and flat scraper (40 $\mathrm{cm}$ length) were used to gently remove the medium material at $1 \mathrm{~cm}$ intervals. All the coal particles collected from the top of the bed to 10 $\mathrm{cm}$ depth were combined and recorded as 'floats', and particles collected from 10-20 cm depth were considered 'sinks'. Each test run was repeated at least three times in order to improve the precision and accuracy of the results.

\section{Analytical methods}

Particle density was measured using pycnometry according to ISO 125154:2014. The particle size distribution of the samples was measured in accordance with ISO 13320:2009 using a Malvern Mastersizer 2000 laser particle analyser. The Davis tube test (ISO 8833:1989) was used to determine the 
magnetic content of the medium materials. XRF analysis according to ISO TR 18336:2016 was used to quantify the iron content of the magnetic and nonmagnetic products of the Davis tube test.

Float and sink tests were performed on the feed coal in accordance with ISO 7936:1992 to determine its washability characteristics. The products and discards obtained were subjected to the same test, and the data was used to plot the partition curves for determining the separation efficiency of the process. Ultimate and sulphur analyses of all samples were performed according to ASTM D 5373-02 and ASTM D 4239-05 respectively, using a Leco CHN 628 with add-on $628 \mathrm{~S}$ module. Proximate analyses to determine the inherent moisture, ash content, and volatile matter were conducted in accordance with ASTM D-5142, using samples of approximately $1 \mathrm{~g}$. The fixed carbon for the samples is expressed as $100 \%$ minus (ash content + volatile matter + moisture content). The calorific value was determined using a Leco AC 500 calorimeter in accordance with ASTM D5865-04.

\section{Results and discussion}

Coal and solid medium characterization

The physical properties of the media, including particle size distribution (PSD) and magnetic content, are shown in Table II. The Davis tube was used to separate the magnetic and nonmagnetic fractions in the proposed medium materials at settings ranging between 0.5 and $2.0 \mathrm{~A}$. Pyrrhotite was the only medium out of the four proposed media that had both a magnetic and a nonmagnetic fraction, comprising about $30 \%$ and $70 \%$ respectively.

The results of the physicochemical analyses of the feed coal are depicted in Table II. The RoM coal sample is classified as a very high-ash, low fixed carbon, D3 grade coal with a low volatiles content (Code 3 ) coal according to the South African Standard Classification of Coals.

The XRF analysis conducted on the feed pyrrhotite and magnetic and nonmagnetic fractions from the Davis tube test showed that the magnetic fraction has the highest concentration of iron (Table III). This test further supports the utilization of pyrrhotite as a medium that can be used with magnetite for dense medium coal separation.

\section{Bed fluidization characteristics}

Fluidization characterization tests were carried out to determine the fluidization behaviour for each solid medium. Figure 2 shows an illustration of the pressure drop profile for two of the nine points in the bed, with magnetite as the dense medium material at $20 \mathrm{~cm}$ static bed height.

\begin{tabular}{|c|c|c|c|c|c|c|}
\hline \multicolumn{7}{|l|}{ Table II } \\
\hline & & \multicolumn{5}{|c|}{ Samples } \\
\hline \multicolumn{2}{|c|}{ Analysis } & Magnetite & Pyrrhotite & GBFS & Silica & Coal Rej. \\
\hline PSD & $\begin{array}{l}\text { D10 }(\mu \mathrm{m}) \\
\text { D50 }(\mu \mathrm{m}) \\
\text { D90 }(\mu \mathrm{m})\end{array}$ & $\begin{array}{c}15 \\
113 \\
338\end{array}$ & $\begin{array}{c}83 \\
200 \\
390\end{array}$ & $\begin{array}{c}98 \\
229 \\
409\end{array}$ & $\begin{array}{l}102 \\
232 \\
402\end{array}$ & $\begin{array}{c}92 \\
218 \\
410\end{array}$ \\
\hline Davis tube & $\begin{array}{l}\text { Magnetic \% } \\
\text { Nonmag. \% }\end{array}$ & $\begin{array}{c}100 \\
0\end{array}$ & $\begin{array}{l}30 \\
70\end{array}$ & $\begin{array}{c}0 \\
100\end{array}$ & $\begin{array}{c}0 \\
100\end{array}$ & $\begin{array}{c}0 \\
100\end{array}$ \\
\hline \multicolumn{7}{|c|}{ Feed coal } \\
\hline Proximate & $\begin{array}{c}\text { (As-received) } \\
\text { (dry basis) }\end{array}$ & $\begin{array}{c}\mathrm{FC} \mathrm{( \% )} \\
38.77 \\
39.61\end{array}$ & $\begin{array}{c}\text { VM (\%) } \\
19.80 \\
20.23\end{array}$ & \multicolumn{2}{|c|}{$\begin{array}{l}39.32 \\
40.17\end{array}$} & $\begin{array}{c}\text { TM (\%) } \\
2.11 \\
-\end{array}$ \\
\hline \multicolumn{2}{|c|}{ Calorific value } & \multicolumn{5}{|c|}{$18.76 \mathrm{MJ} / \mathrm{kg}$} \\
\hline \multicolumn{2}{|c|}{$\begin{array}{l}\text { Ultimate analysis } \\
\text { (dry basis) }\end{array}$} & $\begin{array}{l}\text { C (\%) } \\
49.40\end{array}$ & $\begin{array}{l}\mathrm{H}(\%) \\
2.57\end{array}$ & $\begin{array}{c}\mathrm{N}(\%) \\
1.20\end{array}$ & $\begin{array}{l}\mathrm{S}(\%) \\
2.49\end{array}$ & $\begin{array}{l}O(\%) \text { * } \\
2.06\end{array}$ \\
\hline
\end{tabular}

${ }^{*}$ By difference $\left[100-\left(\mathrm{H}+\mathrm{C}+\mathrm{N}+\mathrm{Ash}+\mathrm{H}_{2} \mathrm{O}+\mathrm{S}\right)\right]$

FC: fixed carbon; VM: volatile matter; TM: total moisture; GBFS: Granulated blast furnace slag

Table III

XRF analysis results

\begin{tabular}{|l|c|c|c|c|c|c|c|c|c|}
\hline Element & Fe (\%) & S (\%) & Ni (\%) & Si (\%) & Al (\%) & Mg (\%) & Ca (\%) & Na (\%) & Ti (\%) \\
\hline Magnetite & 54.96 & 0.09 & 0.02 & 1.11 & 0.58 & 5.36 & 1.52 & 2.02 & 0.97 \\
\hline Pyrr. feed & 10.66 & 1.03 & 0.16 & 23.93 & 4.41 & 19.55 & 7.05 & 2.32 & 0.41 \\
\hline Pyrr. mag & 21.77 & 6.97 & 0.34 & 17.80 & 2.64 & 23.30 & 4.01 & 2.09 & 0.33 \\
\hline Pyrr. nonmag & 8.35 & 0.67 & 0.35 & 24.62 & 5.61 & 18.11 & 7.77 & 3.52 & 0.41 \\
\hline GBFS * & 0.32 & 0.78 & 0.00 & 21.97 & 9.90 & 11.94 & 23.06 & 3.37 & 0.36 \\
\hline
\end{tabular}

* GBFS: Granulated blast furnace slag 


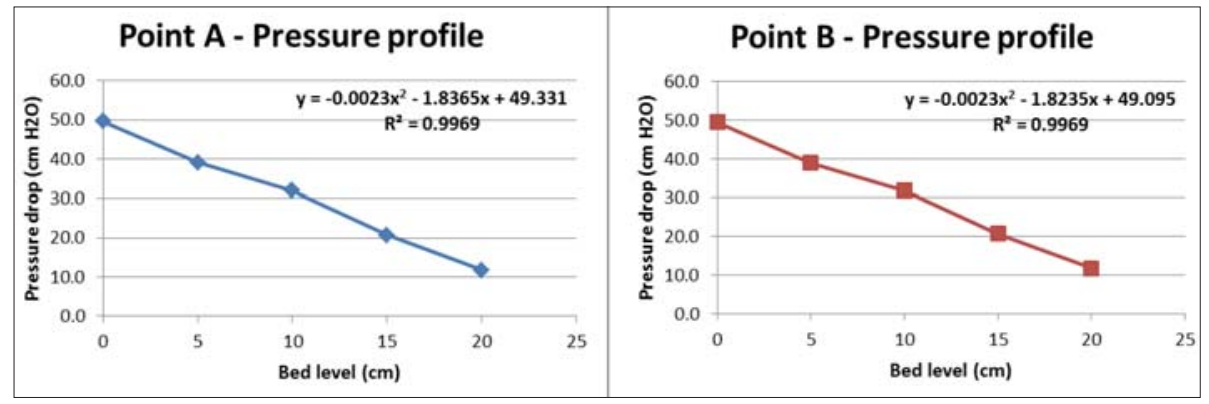

Figure 2-Illustration of pressure drop profiles for two sampling points

The equations below were used to calculate the bed density from the pressure drop profiles (Chikerema, 2011):

$$
\begin{aligned}
& P=-\rho_{\text {bed }} g\left(h_{\text {top }}-h\right) \\
& d P=-\rho_{\text {bed }} g \cdot d h
\end{aligned}
$$

where

$$
\begin{aligned}
& P \text { is the pressure drop }(\mathrm{Pa}) \\
& \rho_{b e d} \text { is the bed density }\left(\mathrm{kg} / \mathrm{m}^{3}\right) \\
& g=9.81 \mathrm{~m} / \mathrm{s}^{2}
\end{aligned}
$$

The gradient of the pressure drop against bed height plot gives the bed density:

$$
\rho_{\text {bed }}=\frac{-(\text { gradient })}{9.81} \times 10^{4}
$$

where 104 is a conversion factor.

The density was determined for each pressure point in the bed and the data was tabulated as shown in Table IV.
Uniformity of the bed density is an important indicator of the stability of a fluidized bed and consequently its ability to provide an efficient separation. Efficient dry separation conditions in an ADMFB are obtained when a stable dispersion, fluidization, and micro-bubbles are achieved. It is very important that the bed density is well distributed in three-dimensional space and does not change with time (Chen and Wei, 2003). The density distribution for different points in the bed utilized in this study was determined by plotting the bed density attained against the bed height. The distribution was analysed vertically per each sampling point and horizontally per each bed level (multiple sampling points).

Figure 3 shows a plot of the vertical distribution of the

\begin{tabular}{|c|c|c|c|c|c|c|c|c|c|}
\hline \multicolumn{10}{|c|}{$\begin{array}{l}\text { Table IV } \\
\text { Bed density distribution for magnetite at } 20 \mathrm{~cm} \text { bed height }\end{array}$} \\
\hline & \multicolumn{9}{|c|}{ Density $\left(\mathbf{k g} / \mathrm{m}^{3}\right)$} \\
\hline $\begin{array}{l}\text { Level } \\
\text { (cm) }\end{array}$ & A & B & C & D & E & $\mathbf{F}$ & G & H & I \\
\hline 0 & 1871 & 1859 & 1859 & 1871 & 1858 & 1870 & 1870 & 1858 & 1862 \\
\hline 5 & 1895 & 1882 & 1882 & 1894 & 1882 & 1894 & 1894 & 1881 & 1884 \\
\hline 10 & 1918 & 1906 & 1906 & 1918 & 1905 & 1917 & 1918 & 1905 & 1905 \\
\hline 15 & 1941 & 1929 & 1929 & 1941 & 1929 & 1941 & 1943 & 1928 & 1926 \\
\hline 20 & 1965 & 1953 & 1952 & 1965 & 1952 & 1964 & 1967 & 1952 & 1948 \\
\hline
\end{tabular}
bed density for two specific pressure points. For pressure point $\mathrm{A}$, the density range was $1871-1965 \mathrm{~kg} / \mathrm{m}^{3}$ with an even distribution $\left(R^{2}=1\right)$ from the bottom to the top of the bed, which was the case for point $B$ and other pressure points taken in this study.
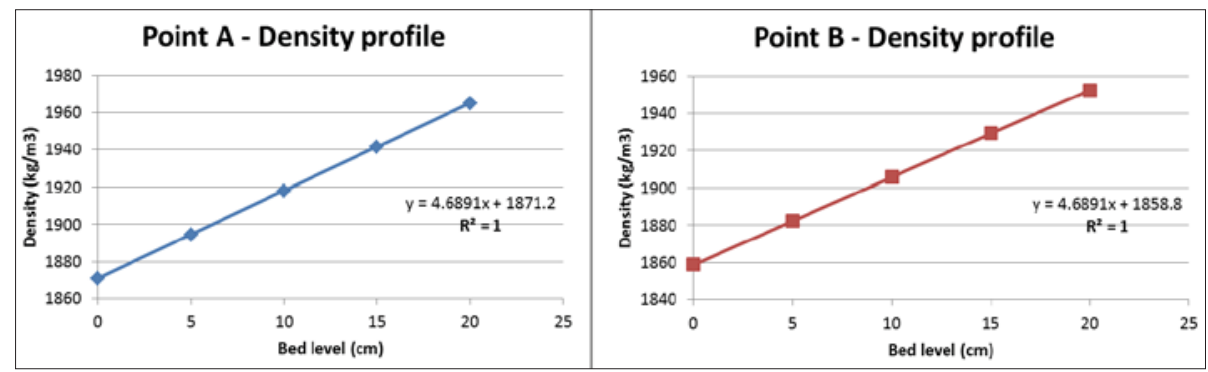


\section{Evaluation of alternative solid media for coal beneficiation using an air dense-medium fluidized bed}

The stability and uniformity of the fluidized bed were established by determining the standard deviation for the density distribution $\left(S_{p}\right)$ for each point (Zhang et al., 2014). $S_{p}$ is given by the following equation:

$$
S_{\rho}=\sqrt{\frac{1}{N}} \sum_{l=1}^{N}\left(\rho_{i}-\bar{\rho}\right)^{2}
$$

where

$\mathrm{N}$ is the total number of sampling points

$\rho_{i} \quad$ is the density of point $i, \mathrm{~g} / \mathrm{cm}^{3}$

$\bar{\rho} \quad$ is the mean density of all points, $\mathrm{g} / \mathrm{cm}^{3}$.

On the other hand, the coefficient of variation $(\mathrm{CoV})$ was also used in this study to further determine the extent of variation of the bed density from its mean at each horizontal bed level. The CoV was calculated by the following equation:

$$
\mathrm{CoV}=\left(\frac{\text { Standard deviation of density for a bed level }}{\text { Average density for that level }}\right) \times 100
$$

Table V shows the standard error $\left(S_{p}\right)$, and CoV for bed density at $20 \mathrm{~cm}$ bed height of magnetite.

Table V shows that the CoV ranges between $0.33-0.37 \%$, while the $S_{p}$ is between $2.05-2.41 \mathrm{~kg} / \mathrm{m}^{3}$, indicating a very stable and uniform bed under these operating conditions. The same procedure was applied to all the solid media proposed as an alternative to magnetite in this study. The data obtained was used to plot the graph of CoV vs. average bed density, as seen in Figure 4.

Figure 4 was used to select the best solid medium and the static bed height at which the bed density is stable and uniform. Magnetite, pyrrhotite, and GBFS at $20 \mathrm{~cm}$ bed height exhibit the most uniform and stable beds, with a coefficient of variation less than $0.7 \%$. However, the GBFS bed had an average density of about $1000 \mathrm{~kg} / \mathrm{m}^{3}$ which, coupled with its lack of magnetism, makes it unsuitable for coal separation as the sole medium but with some potential if blended with magnetite.

\section{ADMFB separator results using magnetite and pyrrhotite ore $(-425+106 \mu \mathrm{m})$}

Magnetite and pyrrhotite were chosen as a solid medium for the initial beneficiation test, using density tracers.

Preliminary results with a magnetite bed alone were used as a baseline for comparison. ADMFB separation was conducted using different static bed heights, and a yield of $55 \%$ and Ep of 0.40 were achieved with a bed height of $20 \mathrm{~cm}$. This bed height was selected for all subsequent tests. Pyrrhotite alone, with a calculated average bed density of $1300 \mathrm{~kg} / \mathrm{m}^{3}$, could not form a bed with an effective cut density for the density tracers $\left(1.2-2.0 \mathrm{~kg} / \mathrm{m}^{3}\right)$ tested. Therefore, a blend of pyrrhotite and magnetite at different weight \% ratios was tested.

\section{Density tracer separation with a blend of pyrrhotite/magnetite}

An investigation was conducted to determine the influence of different blends of magnetite with pyrrhotite on the ADMFB separation efficiency. The blends were prepared using from $20 \%$ to $50 \%$ by weight pyrrhotite, with a bed static height of $20 \mathrm{~cm}$. The best separation results for each blend ratio at the optimum conditions are plotted in Figure 6 . The optimum blend was at $40 \%$ pyrrhotite plus $60 \%$ magnetite, with the yield ranging between $53-58 \%$ and probable error $0.053-$ 0.073 . At higher proportions of pyrrhotite, the yield and separation efficiency began to decline. Therefore, the established optimum operating parameters of $12 \mathrm{~cm} / \mathrm{s}$ superficial air velocity, $20 \mathrm{~cm}$ static bed height, and 20 seconds separation time were then utilized for the separation of coal at this optimum blending ratio.

\section{Coal separation with magnetite and pyrrhotite/ magnetite beds}

The RoM material was first subjected to sink/float analysis in

\begin{tabular}{|c|c|c|c|c|c|}
\hline \multirow[b]{2}{*}{ Pressure point } & \multicolumn{5}{|c|}{ Density (kg/m³) } \\
\hline & $0 \mathrm{~cm}$ & $5 \mathrm{~cm}$ & $10 \mathrm{~cm}$ & $15 \mathrm{~cm}$ & $20 \mathrm{~cm}$ \\
\hline A & 1871 & 1895 & 1918 & 1941 & 1965 \\
\hline B & 1859 & 1882 & 1906 & 1929 & 1953 \\
\hline $\mathrm{C}$ & 1859 & 1882 & 1906 & 1929 & 1952 \\
\hline $\mathrm{D}$ & 1871 & 1894 & 1918 & 1941 & 1952 \\
\hline$E$ & 1858 & 1882 & 1905 & 1929 & 1952 \\
\hline $\mathrm{F}$ & 1870 & 1894 & 1917 & 1941 & 1964 \\
\hline $\mathrm{G}$ & 1870 & 1894 & 1918 & 1943 & 1967 \\
\hline $\mathrm{H}$ & 1858 & 1881 & 1905 & 1928 & 1952 \\
\hline I & 1862 & 1884 & 1905 & 1926 & 1948 \\
\hline $\operatorname{CoV}(\%)$ & 0.33 & 0.34 & 0.35 & 0.37 & 0.37 \\
\hline $\mathrm{Sp}\left(\mathrm{kg} / \mathrm{m}^{3}\right)$ & 2.05 & 2.13 & 2.24 & 2.37 & 2.41 \\
\hline
\end{tabular}
order to evaluate the potential of the ADMFB for cleaning 


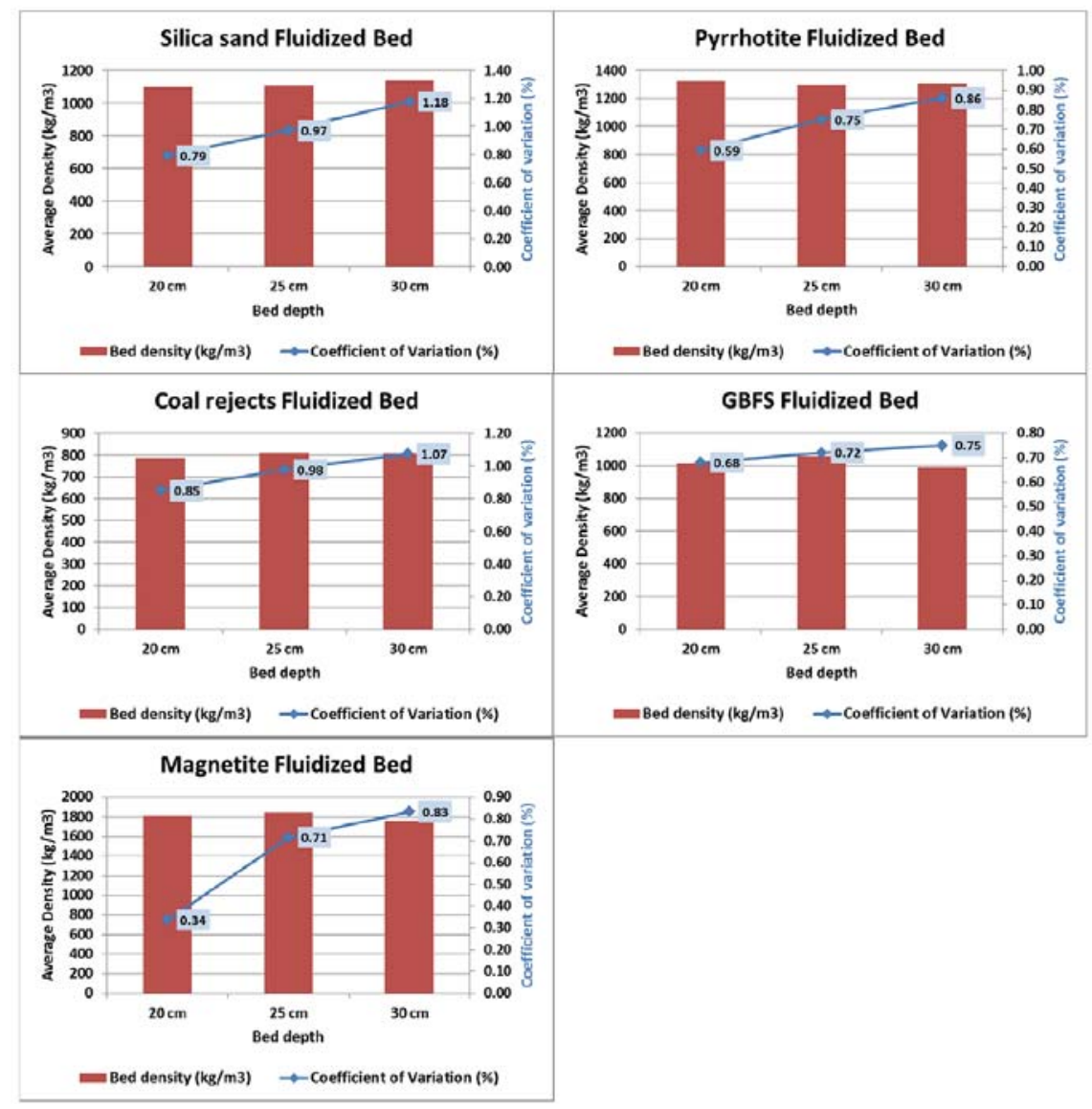

Figure 4-Summary of fluidized bed properties of the solid media

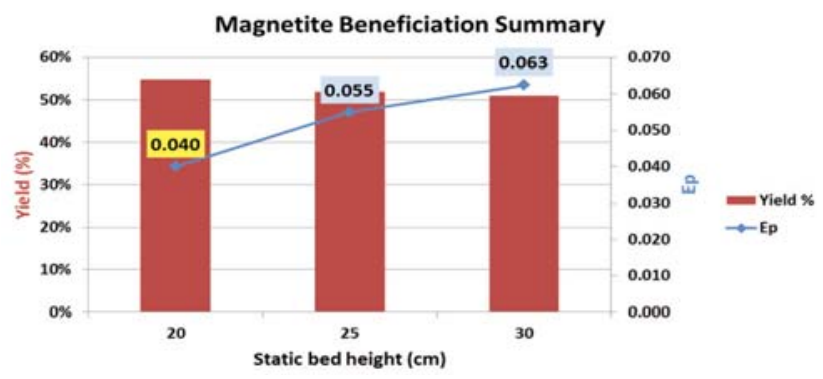

Figure $5-$ Results of beneficiation tests using magnetite as solid medium

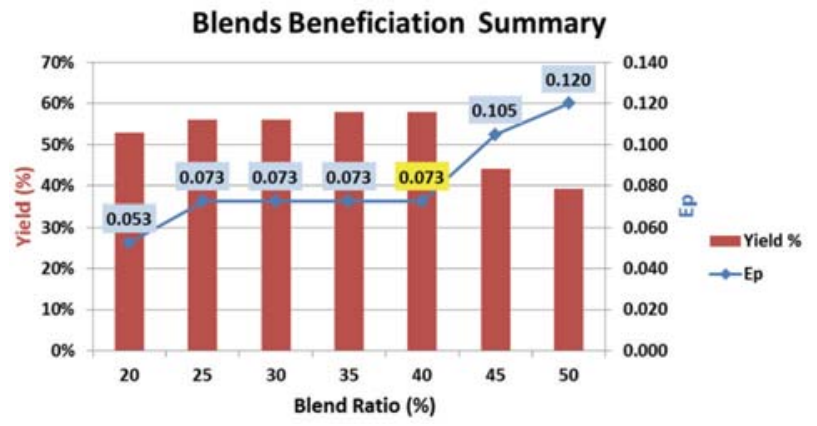

Figure 6-Beneficiation results from the blends of pyrrhotite/magnetite

coal under different conditions. A 100\% magnetite fluidized bed at an optimum operating fluidization velocity $U_{o f}$ of approximately $1.4 U_{m f}$ and $20 \mathrm{~cm}$ static bed height was utilized, and the result compared with that obtained with the blend of pyrrhotite/magnetite.

From the sink and float analysis (Table VI), it can be seen that clean coal of $5.54 \%$ ash with a yield of $1.18 \%$ is obtainable at $1.3 \mathrm{RD}$. In addition, at an RD of 1.5 , clean coal with an ash content of $13.96 \%$ and yield of $23.81 \%$ was also obtained.

As depicted in Figures 7 and 8, at a cut-point/separation density $(\rho 50)$ of about $1.81-1.82 \mathrm{~g} / \mathrm{cm}^{3}$ for the $100 \%$ magnetite bed, coal products with a yield and Ep ranging between $60.26-60.89 \%$ and $0.070-0.075$, respectively were obtained. The product was a clean coal with an ash content of $19.60-20.95 \%$ and calorific value of $25.01-25.46 \mathrm{MJ} / \mathrm{kg}$.

According to Figure 9, a dense medium of $40 \%$ pyrrhotite plus $60 \%$ magnetite blend produced clean coal with a error probable (Ep) between $0.080-0.083$ and yield ranging between 52.04 and $52.67 \%$.

The bed's cut-point/separation density $(\rho 50)$ was at $1.63-1.64 \mathrm{~g} / \mathrm{cm}^{3}$ (Figure 10). The ash content of the feed coal was reduced from $39.32 \%$ to $14.21-14.75 \%$ (an overall ash reduction of $62.49-63.86 \%$, while the feed sulphur content was reduced from $2.49 \%$ to $0.41-0.42 \%$. The calorific value of the product was $26.77-27.58 \mathrm{MJ} / \mathrm{kg}$.

The lower ash products obtained with the $40 \%$ pyrrhotite bed were a result of the lower $\rho 50$ of the bed compared to $100 \%$ magnetite, for which the $\rho 50$ was $1.81-1.82 \mathrm{~g} / \mathrm{cm}^{3}$. These results indicate that pyrrhotite has potential for use in mixed solid media for ADMFB beneficiation. 
Evaluation of alternative solid media for coal beneficiation using an air dense-medium fluidized bed

\begin{tabular}{|c|c|c|c|c|c|c|c|}
\hline \multicolumn{8}{|l|}{$\begin{array}{l}\text { Table VI } \\
\text { ADMFB s }\end{array}$} \\
\hline & & $\begin{array}{l}\text { Ash } \\
(\%)\end{array}$ & $\begin{array}{c}\mathrm{CV} \\
(\mathrm{MJ} / \mathrm{kg})\end{array}$ & $\begin{array}{l}\text { VM } \\
(\%)\end{array}$ & $\begin{array}{l}\text { Yield } \\
(\%)\end{array}$ & $\begin{array}{c}\text { Ash reduction } \\
(\%)\end{array}$ & $\begin{array}{c}\text { S } \\
(\%)\end{array}$ \\
\hline & & 39.32 & 18.76 & 19.80 & 100 & 0.00 & 2.49 \\
\hline $\begin{array}{l}\text { ADMFB } \\
40 \% \\
\text { pyrrhotite }\end{array}$ & $\begin{array}{l}\text { Product } 1 \\
\text { Product } 2 \\
\text { Product } 3\end{array}$ & $\begin{array}{l}14.75 \\
14.21 \\
14.54\end{array}$ & $\begin{array}{l}27.60 \\
26.77 \\
27.58\end{array}$ & $\begin{array}{l}24.14 \\
23.55 \\
25.09\end{array}$ & $\begin{array}{l}52.36 \\
52.18 \\
52.20\end{array}$ & $\begin{array}{l}62.49 \\
63.86 \\
63.12 \\
\end{array}$ & $\begin{array}{l}0.42 \\
0.41 \\
0.42\end{array}$ \\
\hline $\begin{array}{l}\text { ADMFB } \\
100 \% \\
\text { magnetite }\end{array}$ & $\begin{array}{l}\text { Product } 1 \\
\text { Product } 2 \\
\text { Product } 3\end{array}$ & $\begin{array}{l}19.60 \\
20.20 \\
20.95\end{array}$ & $\begin{array}{l}25.46 \\
25.24 \\
25.01\end{array}$ & $\begin{array}{l}22.50 \\
21.99 \\
22.24\end{array}$ & $\begin{array}{l}60.26 \\
60.67 \\
60.89\end{array}$ & $\begin{array}{l}50.15 \\
48.63 \\
46.72\end{array}$ & \\
\hline $\begin{array}{l}\text { Float and } \\
\text { sink test }\end{array}$ & $\begin{array}{l}F @ 1.30 \\
F @ 1.40 \\
F @ 1.50 \\
F @ 1.60 \\
F @ 1.70 \\
F @ 1.80 \\
F @ 1.86 \\
S @ 1.86\end{array}$ & \begin{tabular}{c|}
5.54 \\
8.29 \\
13.96 \\
22.05 \\
32.06 \\
38.56 \\
42.79 \\
76.53
\end{tabular} & $\begin{array}{c}31.47 \\
30.47 \\
27.70 \\
24.10 \\
19.83 \\
17.73 \\
15.81 \\
4.08\end{array}$ & \begin{tabular}{l|}
28.31 \\
26.72 \\
23.06 \\
22.00 \\
18.60 \\
18.84 \\
16.14 \\
10.70
\end{tabular} & \begin{tabular}{c|}
1.18 \\
13.99 \\
23.81 \\
10.04 \\
6.90 \\
6.55 \\
2.45 \\
35.08
\end{tabular} & & \\
\hline
\end{tabular}

* CV: calorific value; VM: volatile matter; F: float; S: sink

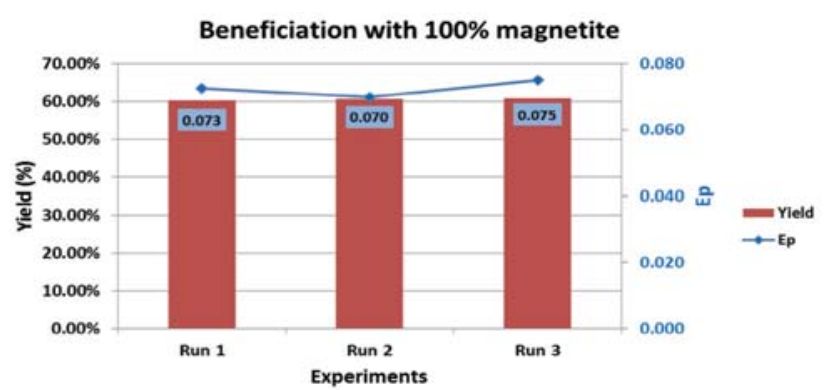

Figure 7-Coal beneficiation results with $100 \%$ magnetite bed

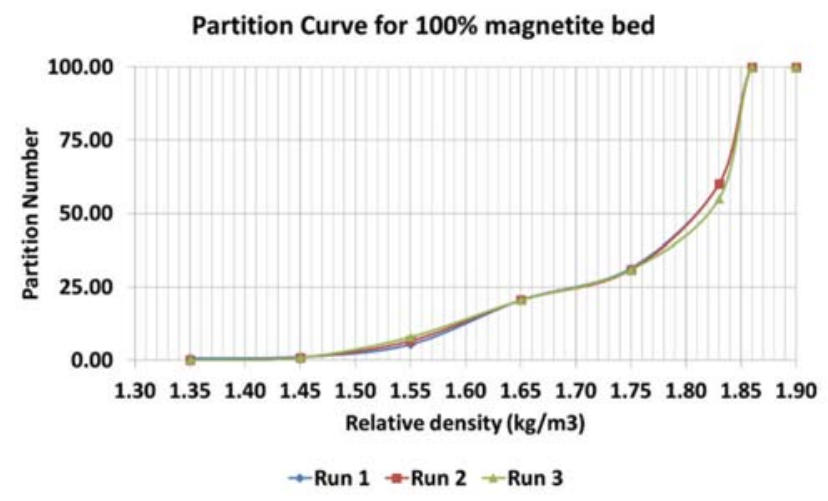

Figure 8-Coal beneficiation partition curve with $100 \%$ magnetite bed

\section{Conclusion}

Pyrrhotite has proved to be the superior dense medium material among the materials proposed as an alternatives to magnetite. The most uniform and stable bed densities were

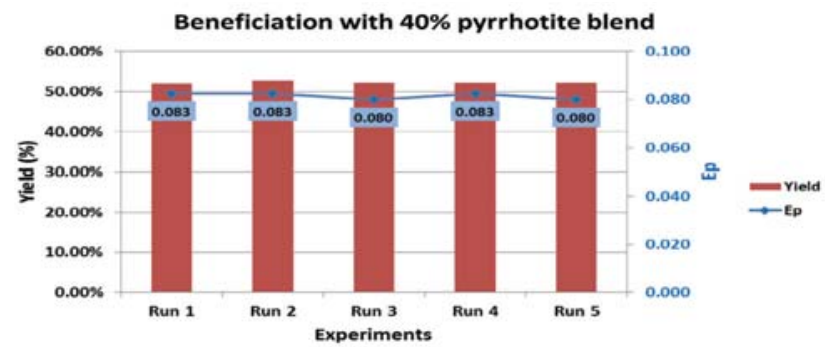

Figure $9-$ Coal beneficiation results with $40 \%$ pyrrhotite blend

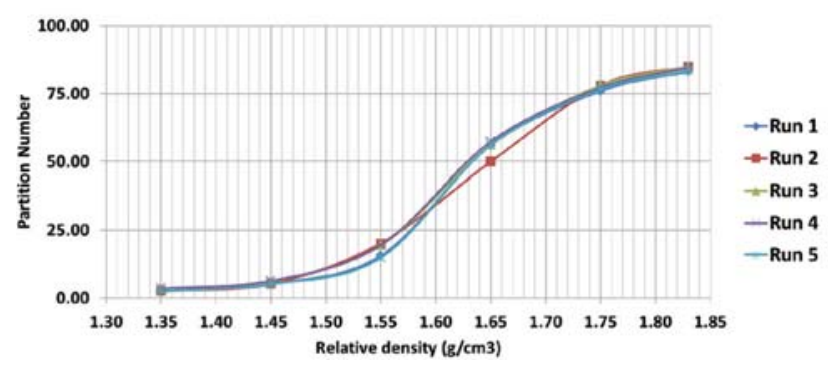

Figure $10-$ Coal beneficiation partition curve with $40 \%$ pyrrhotite blend

achieved using a blend of pyrrhotite (40\%) and magnetite (60\%). A cleaner coal product with less ash and sulphur content was obtained from this blend compared to using magnetite alone. Using a $40 \%$ pyrrhotite bed, feed ash content was reduced from $39.32 \%$ to about $14.50 \%$ and the product coal had a calorific value of about $27.30 \mathrm{MJ} / \mathrm{kg}$. The $100 \%$ magnetite bed produced a product with an ash content of about $20.30 \%$ and calorific value of about $25.24 \mathrm{MJ} / \mathrm{kg}$.

The blending of pyrrhotite, which is considered a reject 'no-cost' material, with magnetite could reduce the cost of operating a coal ADMFB process significantly. 


\section{Evaluation of alternative solid media for coal beneficiation using an air dense-medium fluidized bed}

\section{Acknowledgments}

The authors acknowledge, with thanks, the financial support of Coaltech Research Association (Project No: $4.8 .5 \mathrm{c}$ ) and the Clean Coal and Sustainable Energy Group of the University of the Witwatersrand. Our gratitude also goes to the University of the Witwatersrand for access to research facilities.

\section{References}

Azimi, E., Karimipour, S., Rahman, M., Szymanski, J., and Gupta, R. 2013 Evaluation of the performance of air dense medium fluidized bed (ADMFB) for low-ash coal beneficiation. Part 1: Effect of operating conditions. Energy \& Fuels, vol. 27, no. 10. pp. 5595-5606.

Chen, Q. and Wer, L. 2003. Coal dry beneficiation technology in China: the state-of-the-art. China Particuology, vol. 1, no. 2. pp. 52-56.

Chikerema, P. 2011. Effects of particle size, shape and density on the performance of an air fluidized bed in dry coal beneficiation. MSc dissertation, University of the Witwatersrand, Johannesburg, South Africa.

Dwari, R.K. and Rao, K.H. 2007. Dry beneficiation of coal-a review. Mineral Processing and Extractive Metallurgy Review, vol. 28, no. 3. pp. 177-234.

FAn, M., Chen, Q., Zhao, Y., and Luo, Z. 2001. Fine coal (6-1 mm) separation in magnetically stabilized fluidized beds. International Journal of Mineral Processing, vol. 63, no. 4. pp. 225-232.

Firdaus, M., O'Shea, J.-P., Oshitani, J., and Franks, G.V. 2012. Beneficiation of coarse coal ore in an air-fluidized bed dry dense-medium separator.
International Journal of Coal Preparation and Utilization, vol. 32, no. 6. pp. 276-289.

Fraser, T. and Yancey, H. 1926. Artificial storm of air-sand floats coal on its upper surface, leaving refuse to sink. Coal Age. pp. 325-327.

Hancox, P.J. and GöTZ, A.E. 2014. South Africa's coalfields - A 2014 perspective. International Journal of Coal Geology, vol. 132. pp. 170-254.

HoNAKER, R.Q. and Bimpong, C. 2009. Alternative materials for dense medium separations. International Journal of Coal Preparation and Utilization, vol. 29, no. 4. pp. 173-191.

Luo, Z., ZHu, J., FAN, M., ZHAO, Y., and TAO, X. 2007. Low density dry coal beneficiation using an air dense medium fluidized bed. Journal of China University of Mining and Technology, vol. 17, no. 3. pp. 306-309.

Prevost, X.M. 2015. Coal in the global and Southern African context. Fossil Fuel Foundation. http:// www.fossilfuel.co.za/conferences/2015/JCMV$\mathrm{X} /$ Session-1/02Xavier-Prevost.pdf

Zhang, B., Zhao, Y., Luo, Z., Song, S., Li, G., and Sheng, C. 2014. Utilizing an air-dense medium fluidized bed dry separating system for preparing a low-ash coal. International Journal of Coal Preparation and Utilization, vol. 34, no. 6. pp. 285-295.

Zhao, Y., Li, G., Luo, Z., Zhang, B., Dong, L., Liang, C., and Duan, C. 2016. Industrial application of a modularized dry-coal-beneficiation technique based on a novel air dense medium fluidized bed. International Journal of Coal Preparation and Utilization, vol. 37, no. 1. pp. 1-14.

Zhao, Y.M., Liu, X.J., Liu, K.L., Luo, Z.F., Wu, W.C., Song, S.L., and TANG, L.G. 2011. Fluidization characteristics of a gas-paigeite-powder bed to be utilized for dry coal beneficiation. International Journal of Coal Preparation and Utilization, vol. 31, no. 3-4. pp. 149-160.

\section{SAIMM Journal}

Advertisement Bookings

Barbara Spence · Avenue Advertising

PO Box 71308, Bryanston, 2021

Tel: 0114637940 - Cell: 0828813454

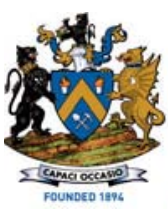

YPC (Young Professionals Council) Handbook

YIMM (Youth in Mining and Metallurgy) Magazine

The SAIMM offers businesses wanting to reach decision-makers, thought-leaders and key opinion-formers in the mining environment different opportunities and essential platforms to do so.

Include the SAIMM in your marketing plan if you want to get noticed, grow your market share and assure your existing client base that they are dealing with the right service provider.

The SAIMM's monthly, highly regarded Journal, website and various specialist magazines are distinctly differentiated from other available commercial mining publications, and online digital avenues.

The SAIMM offerings are essential for the mining industry, representing cutting-edge research and thinking that is a must for professionals in the minerals industry who are serious about their work portfolios. Our platforms are not diluted by advertorials or press-releases and our content is peer-reviewed and accredited by acknowledged authorities, specialists and industry experts.

'Content is king' and our content is 'must read'.

Attractive package deals across all platforms can be negotiated. 